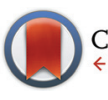

CrossMark \& click for updates

Cite this: Polym. Chem., 2016, 7, 6934

Received 3rd October 2016, Accepted 18th October 2016 DOI: 10.1039/c6py01730d www.rsc.org/polymers

\section{Grafting of functional methacrylate polymer brushes by photoinduced SET-LRP $\uparrow$}

\author{
Mariia Vorobii, $\ddagger^{\mathrm{a}}$ Ognen Pop-Georgievski, $\$^{\mathrm{b}}$ Andres de los Santos Pereira, \\ Nina Yu. Kostina, ${ }^{a}$ Ryan Jezorek, ${ }^{c}$ Zdeňka Sedláková, ${ }^{b}$ Virgil Percec ${ }^{\star c}$ and \\ Cesar Rodriguez-Emmenegger ${ }^{\star a, c}$
}

Photoinduced surface-initiated single electron transfer living radical polymerization (SET-LRP) is a versatile technique for the preparation of polymer brushes. The vast diversity of compatible functional groups, together with a high end-group fidelity that enables precise control of the architecture, makes this approach an effective tool for tuning the properties of surfaces. We report the application of photoinduced SET-LRP for the surface-initiated grafting of polymer brushes from a wide range of methacrylate monomers for the first time. The living character of the process was demonstrated by the linear evolution of the polymer brush thickness in time, the ability to reinitiate the polymerization for the preparation of well-defined block copolymers, and also by X-ray photoelectron spectroscopy depth profiling. The surface patterning with these brushes could be achieved simply by restricting the irradiated area. The ability of poly(methacrylate) brushes prepared in this way to prevent non-specific protein adsorption is also demonstrated, indicating the suitability of this procedure for advanced applications.

\section{Introduction}

Polymer brushes are ultrathin polymer coatings, formed by highly packed polymer chains that are tethered by one end to a surface or interface. ${ }^{1,2}$ The diversity of polymers and their functional groups makes them a powerful tool to achieve control of the properties of surfaces. ${ }^{3-5}$ As an example, covering the surface with polymer brushes could suppress nonspecific protein adsorption (protein fouling) from biological media $^{6-8}$ as well as decrease the forces of bacterial adhesion on the surface. ${ }^{9}$ These properties are interesting for use in medical devices, such as artificial heart valves, catheters, or other indwelling devices to prevent bacterial infections and to avoid the formation of blood clots. Particularly in affinity biosensors, antifouling polymer brushes are used to eliminate the non-specific response in complex biological matrices, ${ }^{10,11}$

\footnotetext{
${ }^{a}$ DWI - Leibniz-Institute for Interactive Materials and Institute of Technical and Macromolecular Chemistry, RWTH Aachen University, Forckenbeckstraße 50, 52074 Aachen, Germany.E-mail: rodriguez@dwi.rwth-aachen.de

${ }^{b}$ Department of Chemistry and Physics of Surfaces and Biointerfaces,

Institute of Macromolecular Chemistry, Academy of Sciences of the Czech Republic, v.v.i., Heyrovsky sq. 2, 16206 Prague, Czech Republic

${ }^{c}$ Roy \& Diana Vagelos Laboratories, Department of Chemistry,

University of Pennsylvania, Philadelphia, Pennsylvania 19104-6323, USA.

E-mail:percec@sas.upenn.edu

$\dagger$ Electronic supplementary information (ESI) available. See DOI: 10.1039/ c6py01730d

$\$$ These authors contributed equally to this work.
}

including blood plasma, ${ }^{12}$ to allow for label-free detection. ${ }^{13,14}$ At the same time, polymer brushes have also been employed as a platform for selective protein binding and applied for protein purification. ${ }^{15}$

There are two main strategies for the preparation of polymer brushes: "grafting to" and "grafting from", which are compatible with a wide diversity of substrates and nanomaterials. ${ }^{16}$ Since the grafting-to approach is based on the attachment of large end-functionalized polymer chains that must diffuse through the formed polymer film to reach the reactive groups on the surface, this strategy cannot yield very dense and thick polymer brushes. ${ }^{2,15,17}$ On the other hand, the grafting-from approach, based on direct polymerization typically from initiator-functionalized surfaces, allows achieving very dense polymer brushes and good control over the thickness, composition and architecture. ${ }^{18,19}$ Among different living polymerization techniques employed for this purpose, including cationic and anionic polymerizations ${ }^{18}$ and ringopening polymerization, ${ }^{20}$ the most frequently used methods are controlled radical polymerization techniques: ${ }^{17}$ surfaceinitiated atom transfer radical polymerization (SI-ATRP), ${ }^{21,22}$ surface reversible addition-fragmentation chain transfer polymerization (S-RAFT), ${ }^{20,23}$ surface-initiated nitroxidemediated polymerization (SI-NMP), ${ }^{24-26}$ and surface-initiated photoiniferter-mediated polymerization (SI-PIMP). ${ }^{27,28}$ A promising new technique for the preparation of polymer brushes is single-electron transfer living radical polymerization (SET-LRP). ${ }^{29-34}$ Typical for this approach are very fast polymer- 
ization kinetics at room temperature ${ }^{29,35,36}$ and below ${ }^{37,38}$ with very low catalyst concentrations. ${ }^{39-41}$ SET-LRP is compatible with monomers containing various functional groups, ${ }^{42}$ as well as with different solvents such as dimethyl sulfoxide (DMSO), ${ }^{43,44}$ alcohols, fluorinated alcohols, ${ }^{45,46}$ ionic liquids, water, and mixtures. ${ }^{39,47,48}$ Moreover, it was recently extended to mixtures of non-disproportionating solvents with water. ${ }^{49}$ SET-LRP is characterized by perfect or near-perfect chain-end fidelity $^{33,50}$ which is critical for the control of the polymer architecture via end group modification, re-initiation and preparation of multiblocks. ${ }^{40}$ Interestingly, even RAFT agents could be used as initiators for SET-LRP instead of the typical alkyl halides. ${ }^{51}$

In the past decade, great interest has been raised over surface modifications, enabling the patterning of polymers, and also development of multifunctional surfaces. Among the applications that require such capabilities are biosensors, presenting areas of varying functionality or multiple sensing regions. ${ }^{52}$ The most commonly used strategies for the preparation of patterns are: photo and interference lithography, electron-beam lithography, scanning probe lithography, soft lithography, and other lithographic approaches. ${ }^{53}$ Photolithography is particularly attractive for several of its advantages, ${ }^{17}$ since relatively large areas can be easily and rapidly patterned. Furthermore, the decreased contact time lowers the risk of contamination in comparison with contact writing techniques. One way to use this approach is in combination with surfaceinitiated polymerization to prepare binary polymer brush patterns. ${ }^{53,54}$ Binary polymer brushes are interesting because of their ability to adjust their morphology in response to changes in their surrounding environment. ${ }^{55-58}$

Recently, photoinduced surface-initiated SET-LRP was introduced, merging the advancements in living radical polymerization of activated monomers with the enhanced control over the process that is enabled by the use of UV light as a polymerization trigger. ${ }^{39,41,59-63}$ This has several benefits, including direct spatial control over polymer growth and regulation of the molecular weight by control of the intensity of illumination. ${ }^{64}$ The translation of this promising approach to the surface-initiated grafting of polymer brushes has led to micropatterns, while preserving the living character of the polymerization and enabling the formation of block copolymers. ${ }^{41,65}$ This technique was applied to a wide range of acrylate monomers of various functionalities, constituting the fastest surface-initiated polymerization reported thus far and reaching unprecedented thicknesses of up to $1 \mu \mathrm{m}$ within $1 \mathrm{~h}$ of polymerization. $^{41}$ Moreover, using this protocol, polymer brushes of $\mathrm{N}$-(2-hydroxypropyl)methacrylamide (HPMA) could be obtained, while its surface-initiated polymerization proceeded in a living manner for the first time. ${ }^{65}$ Consequently, this methodology holds vast potential for the controlled grafting of various types of functional polymer brushes.

Particularly important families of monomers that have been used to tailor surface functionality are those including a methacrylate polymerizable group..$^{10,11,66-68}$ Several such monomers have already been used for the modification of surfaces. For example, polymer brushes obtained from oligo(ethylene glycol) methyl ether methacrylate (MeOEGMA), 2-hydroxypropyl methacrylate (HPM), ${ }^{6}$ and 2-hydroxyethyl methacrylate (HEMA) ${ }^{11,69}$ are well known for their antifouling properties. They prevent nonspecific protein adsorption from single-protein solutions and reduce fouling of human blood plasma up to $90 \%$ in comparison with bare gold. Poly[2-(dimethylamino)ethyl methacrylate] (DMAEMA) was grafted from cellulose paper and the surfaces obtained were used to detect DNA hybridization. ${ }^{70}$ Moreover, poly(DMAEMA) brushes can be used to prepare stimuli-responsive surfaces, as they are able to change their conformation in response to temperature changes in a pH-dependent manner. ${ }^{71,72}$ Thus, there is considerable interest in the development of improved surfaceinitiated polymerization protocols for such monomers. Additionally, introducing light as a control mechanism to spatially confine the polymerization would enable the facile fabrication of (micro)patterned poly(methacrylate) brushes.

In this report, we present the use of photoinduced SET-LRP for the surface-initiated grafting of polymer brushes from a wide range of methacrylate monomers presenting various functionalities. We investigated the influence of varying the solvent composition and the concentration of the Cu-based catalyst on the polymerization process. Additionally, we demonstrate the livingness of the process when applied to methacrylate monomers, as well as the ability to create surface patterns of polymer brushes by a simple photolithographic approach.

\section{Results and discussion}

\section{Grafting of methacrylate polymer brushes}

Photoinduced SET-LRP was used for the preparation of polymer brushes from a variety of methacrylate monomers on silicon wafer chips as a model substrate. The process can be divided in two steps: firstly, a self-assembled monolayer (SAM) of the initiator is formed, and secondly, the photoinduced polymerization of each monomer is carried out.

For the preparation of the SAM, 11-(trichlorosilyl)undecyl 2-bromo-2-methylpropanoate was chosen as the initiator, as it has been shown to lead to the formation of well-defined monolayers. This is an essential requirement for the stable grafting of dense brushes. The silicon substrates were freshly activated with air plasma and immersed in a solution of the initiator in dry toluene to form the SAM (Scheme 1).

Dynamic water contact angle, atomic force microscopy (AFM), X-ray photoelectron spectroscopy (XPS), and spectroscopic ellipsometry were used to confirm the successful grafting of the initiator layer. The formation of the SAM is confirmed by a change in the surface wettability as measured by sessile-drop dynamic water contact angle goniometry, from fully wettable freshly plasma-cleaned silicon substrates to markedly more hydrophobic for the $\operatorname{SAM}\left(\theta_{\mathrm{adv}}=83^{\circ}\right.$ and $\theta_{\mathrm{rec}}=$ $77^{\circ}$ ). This result is expected due to the chemical structure of the initiator, containing a long alkyl backbone. The thickness 

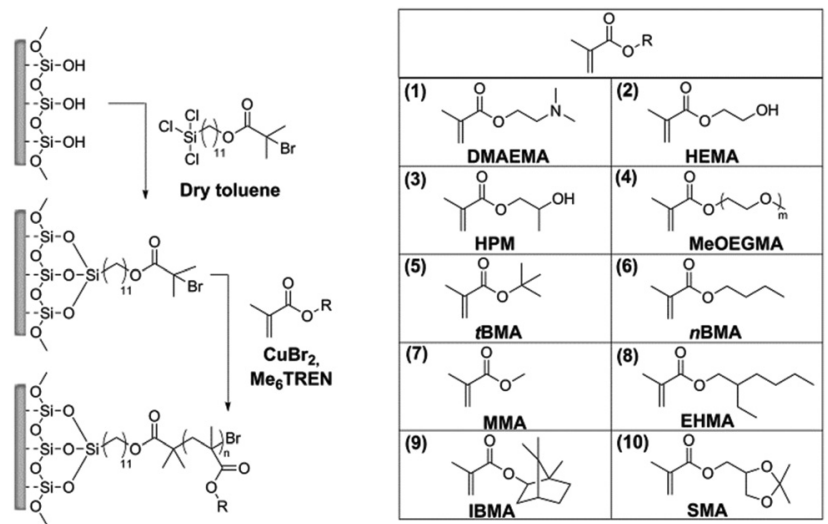

Scheme 1 Surface-initiated photoinduced SET-LRP of methacrylates. (1) 2-(Dimethylamino)ethyl methacrylate (DMAEMA), (2) 2-hydroxyethyl methacrylate (HEMA), (3) 2-hydroxypropyl methacrylate (HPM), (4) oligo (ethylene glycol) methyl ether methacrylate (MeOEGMA), (5) $t$-butyl methacrylate (tBMA), (6) $n$-butyl methacrylate ( $n B M A),(7)$ methyl methacrylate (MMA), (8) 2-ethylhexyl methacrylate (EHMA), (9) isobornyl methacrylate (IBMA), and (10) solketal methacrylate (SMA).

of the initiator layer was determined to be $(0.97 \pm 0.04) \mathrm{nm}$ by ellipsometry, which is consistent with the presence of a monolayer. AFM topography images show homogeneous coverage and a low roughness of $R_{\mathrm{q}}=1.14 \mathrm{~nm}$ (see the ESI, Fig. SF1 $\dagger$ ). The chemical composition of the SAM was confirmed by XPS. The XPS spectrum of the $\mathrm{C}$ 1s region (Fig. 1a) shows the predominance of the $\underline{\mathrm{C}}-\mathrm{C}, \underline{\mathrm{C}}-\mathrm{H}$ component at $285.0 \mathrm{eV}$, attributed to the alkane backbone of the initiator SAM. The resolved contributions of the envelope at 284.2, 286.7 and 289.2 eV correspond to the $\underline{\mathrm{C}}-\mathrm{Si}$ bond, the carbon atoms of the $\underline{\mathrm{C}}-\mathrm{O}-(\mathrm{C}=\mathrm{O})$ and $\mathrm{Br}-\underline{\mathrm{C}}-(\mathrm{C}=\mathrm{O})-\mathrm{O}$, and the ester group $((\mathrm{C}=\mathrm{O})-\mathrm{O})$, respectively. The presence of $\mathrm{Br}$ groups is further confirmed by the high resolution spectrum of the $\mathrm{Br} 3 \mathrm{~d}$ region (see the ESI, Fig. SF2 $\dagger$ ).

Polymer brushes from various methacrylate monomers were grafted from the obtained initiator layer: 2-(dimethylamino)ethyl methacrylate (DMAEMA), 2-hydroxyethyl methacrylate (HEMA), 2-hydroxypropyl methacrylate (HPM), oligo (ethylene glycol) methyl ether methacrylate (MeOEGMA), $t$-butyl methacrylate ( $t$ BMA), $n$-butyl methacrylate ( $n \mathrm{BMA})$, methyl methacrylate (MMA), 2-ethylhexyl methacrylate (EHMA), isobornyl methacrylate (IBMA), and solketal methacrylate (SMA). The polymer brushes were prepared by immersing the initiator-SAM-coated substrates in a degassed solution of the monomer in DMSO containing $\mathrm{CuBr}_{2}$ and tris[2-(dimethylamino)ethyl]amine ( $\left.\mathrm{Me}_{6} \mathrm{TREN}\right)$ in sealed reactors and subsequently exposing the system to UV light irradiation at ambient temperature (Scheme 1) for a set amount of time. The substrates were subsequently removed from the reactors and rinsed with solvents and then dried. The chemical structures of the obtained polymer brushes were confirmed by XPS. Fig. 1(b)-(k) show the high-resolution $\mathrm{C}$ 1s regions of the spectra. The spectra of all methacrylate polymer brushes show a $\underline{\mathrm{C}}-\mathrm{C}, \underline{\mathrm{C}}-\mathrm{H}$ contribution at $285.0 \mathrm{eV}$. This peak dominates the

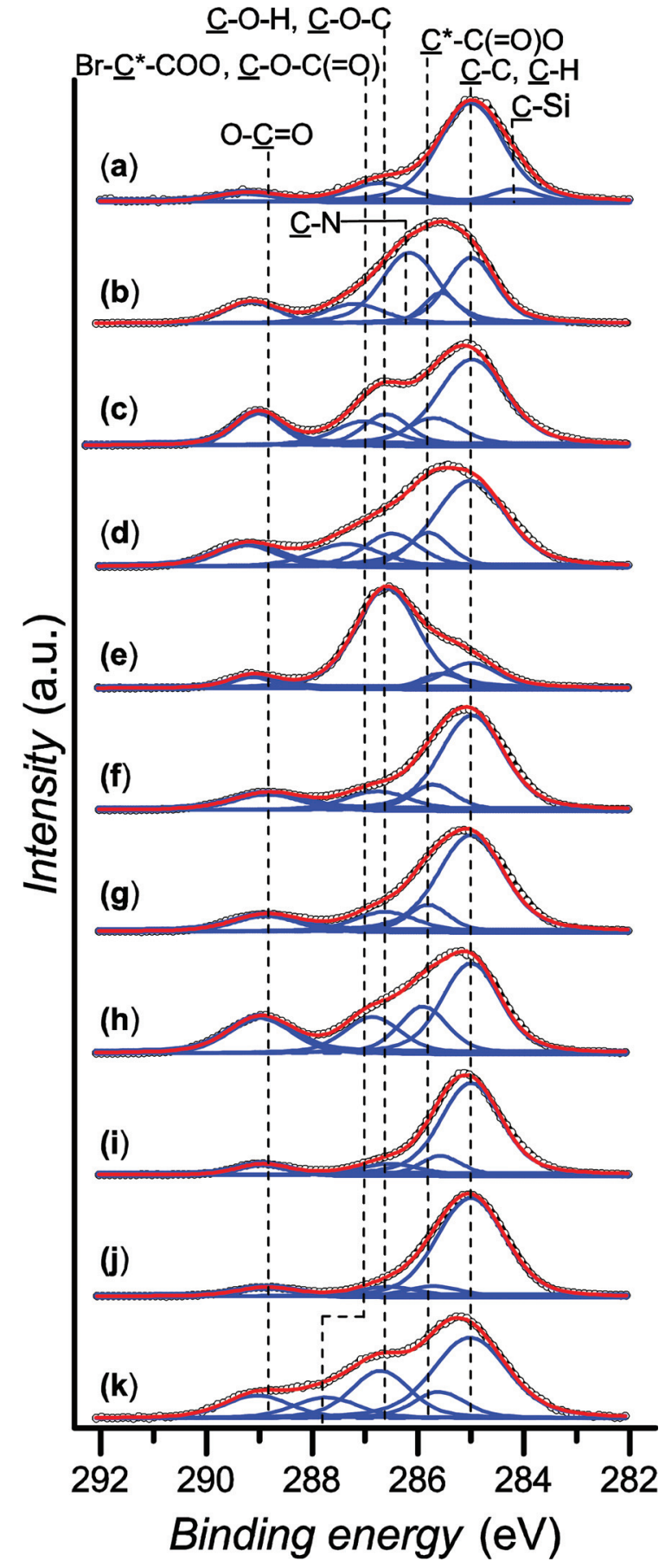

Fig. 1 High-resolution XPS spectra of the $C$ 1s region of (a) the SAM of initiator and the obtained polymer brushes: (b) poly(DMAEMA), (c) poly (HEMA), (d) poly(HPM), (e) poly(MeOEGMA), (f) poly(tBMA), (g) poly (nBMA), (h) poly(MMA), (i) poly(EHMA), (j) poly(IBMA), (k) poly(SMA).

C 1s spectra of poly(HEMA), poly(HPM), poly(tBMA), poly ( $n$ BMA), poly(MMA), poly(IBMA) and poly(SMA) brushes. The C-C, C-H contributions are accompanied by a component at $(285.7 \pm 0.1) \mathrm{eV}$ arising from the secondary chemical shift, i.e. the effect of the ester group on the tertiary carbon atom in the $\mathrm{C}^{*}-(\mathrm{C}=\mathrm{O})-\mathrm{O}-\mathrm{R}$ structure. Furthermore, all polymer brushes 
show a contribution at $(286.9 \pm 0.4)$ eV from $\underline{\mathrm{C}}-\mathrm{O}-(\mathrm{C}=\mathrm{O})$ and a well-resolved ester peak $(\mathrm{O}-\mathrm{C}=\mathrm{O})$ at $(289.0 \pm 0.1) \mathrm{eV}$. In addition to these components, the spectrum of poly (DMAEMA) shows a dominant $\underline{\mathrm{C}}-\mathrm{N}$ peak at $(286.2 \pm 0.1) \mathrm{eV}$. Interestingly, the brushes of monomers having hydroxyl groups in their covalent structure, i.e. HEMA and HPM, exhibit a $\mathrm{C}-\mathrm{O}-\mathrm{H}$ peak at $(286.6 \pm 0.1) \mathrm{eV}$ which is well resolved from the $\underline{\mathrm{C}}-\mathrm{O}-(\mathrm{C}=\mathrm{O})$ contributions. The presence of oligo(ethylene glycol) side chains gives rise to the strongest contribution in the C 1s spectrum of poly(MeOEGMA) brushes at (286.6 \pm 0.1$)$ $\mathrm{eV}$ which for this type of brush seems to overlap with the $\underline{\mathrm{C}}-\mathrm{O}-$ $(\mathrm{C}=\mathrm{O})$ contributions. However, the $\mathrm{C}-\mathrm{O}-\mathrm{C}$ and the $\underline{\mathrm{C}}-\mathrm{O}-$ $(\mathrm{C}=\mathrm{O})$ contributions are well resolved for the poly(SMA) brushes with a separation between the peaks of about $1 \mathrm{eV}$. Notably, the measured ratios between the individual contributions of the $\mathrm{C} 1 \mathrm{~s}$ envelopes for the initiator molecules and polymer brushes match the expected theoretical values within the experimental errors of XPS (see the ESI, Table ST1†). With the exception of poly(DMAEMA), the high resolution $\mathrm{N} 1 \mathrm{~s}$ spectra of all polymer brushes lack contributions from nitrogen (see ESI, Fig. SF4 $\dagger$ ) as expected from their chemical structures. The $\mathrm{N}$ 1s spectrum of poly(DMAEMA) could be resolved with two contributions at $399.1 \mathrm{eV}$ and $399.9 \mathrm{eV}$ arising from the uncharged and charged dimethylamino groups. For all investigated substrates, no signals were observed around $933 \mathrm{eV}$ (see the ESI, Fig. SF5†), demonstrating a quantity of copper on the surfaces below the detection limit of XPS, which is important for any potential biological applications that would be limited by toxicity arising from such contamination.

The dynamic water contact angles were measured for all of the grafted polymer brushes. The changes in wettability correspond to hydrophobicity/hydrophilicity expected from the structure of the polymers. A marked decrease in the advancing and especially in the receding water contact angles is observed for HEMA, HPM, MeOEGMA, and DMAEMA, while on the other hand, polymer brushes of $t$ BMA, $n$ BMA, MMA, EHMA, IBMA, and SMA show poor wettability (see the ESI, Table ST $2 \dagger$ ). The observed contact angle hysteresis is caused by the swelling of the polymer layers upon contact with the water droplet.

The homogeneity of the obtained polymer brush layers was assessed by AFM. The thicknesses of the prepared polymer brushes were found to be homogeneous with low mean square roughness (see the ESI, Table ST3†).

\section{Optimization of the polymerization conditions}

Since the polymerization is confined to the surface, the monomer conversion is negligible even for relatively thick layers of over $100 \mathrm{~nm}$. For this reason, the polymerization kinetics were studied by following the evolution of the brush thickness, as measured by ellipsometry, with polymerization time. DMAEMA was chosen as a model monomer to study the polymerization using various catalyst concentrations and solvent compositions (Fig. 2). The influence of the catalyst concentration (Fig. 2a) was studied in DMSO. The results obtained show that the linear character of the thickness growth is maintained even with a very low concentration of copper $(77 \mathrm{ppb})$.

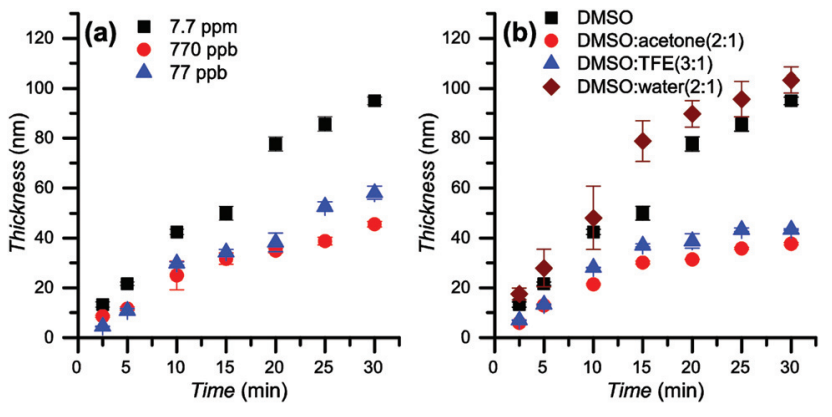

Fig. 2 Polymer thickness of dry poly(DMAEMA) brushes as a function of polymerization time. (a) Effect of $\mathrm{Cu}$ concentration. (b) Effect of the solvent. Polymerization conditions: (a) $[\mathrm{DMAEMA}]=1.68 \mathrm{M}$, solvent DMSO. Catalyst concentration: $\left[\mathrm{CuBr}_{2}\right]=166 \mu \mathrm{M}(7.7 \mathrm{ppm})$ (black squares), $\left[\mathrm{CuBr}_{2}\right]=16.6 \mu \mathrm{M}(770 \mathrm{ppb})$ (red circles), $\left[\mathrm{CuBr}_{2}\right]=16.6 \mu \mathrm{M}$ $(770 \mathrm{ppb})$ (blue triangles), $\left[\mathrm{Me}_{6} \mathrm{TREN}\right]=6 \times\left[\mathrm{CuBr}_{2}\right]$; (b) $[\mathrm{DMAEMA}]=1.68 \mathrm{M}$, $\left[\mathrm{CuBr}_{2}\right]=166 \mu \mathrm{M}(7.7 \mathrm{ppm}),\left[\mathrm{Me}_{6} \mathrm{TREN}\right]=995 \mu \mathrm{M}$. Solvents: DMSO (black squares), DMSO/acetone $2: 1$ (red circles), DMSO/2,2,2-trifluoroethanol (TFE) $3: 1$ (blue triangles), DMSO/water 2: 1 (brown diamonds).

Decreasing the catalyst concentration leads to a reduction in the rate of polymerization.

While photoinduced living radical polymerization of methacrylates has been reported previously, the requirement for catalyst systems based on rare metals such as Ir may be problematic due to availability concerns, potentially impairing its wide adoption. ${ }^{64,73}$ In this regard, copper catalysts are already commonly used in established Cu-mediated living polymerizations. The possibility to perform the polymerization at ppblevel concentrations of catalyst brings this protocol even closer to applications. ${ }^{41}$

The effect of the solvent was studied by comparing the kinetics in DMSO, DMSO/acetone $2: 1, \mathrm{DMSO} / 2,2,2$-trifluoroethanol (TFE) $3: 1$, and DMSO/water $2: 1$ while using $7.7 \mathrm{ppm}$ of copper (Fig. 2b). A linear evolution of the thickness was observed for all conditions in the first $15 \mathrm{~min}$ of irradiation. In the following $15 \mathrm{~min}$ for DMSO/acetone $2: 1$ and DMSO/TFE $3: 1$ a reduction in the rate of polymerization was observed, suggesting the presence of termination processes during the polymerization. Thus, these conditions were not employed for other monomers. The highest rate of polymerization was observed in DMSO/water $2: 1$, leading to a brush thickness of more than $100 \mathrm{~nm}$ in $30 \mathrm{~min}$. However, the obtained brush thicknesses were less homogeneous over the surfaces in comparison with brushes grown using neat DMSO as a solvent, detected by a higher deviation of the thickness measured in different spots on individual samples (up to $13 \mathrm{~nm}$ for DMSO/ water $v$ s. less than $2.8 \mathrm{~nm}$ in pure DMSO). Linear polymerization kinetics were observed in DMSO. A thickness of $100 \mathrm{~nm}$ was reached in only $30 \mathrm{~min}$. AFM topography images reveal that the surface was smooth and homogeneous (see ESI, Table ST $3 \dagger$ ).

In order to demonstrate the importance of each component of the polymerization system, a series of blank experiments was carried out. The individual removal of either the UV irradiation, the initiator SAM on the substrates, or the catalyst prevented the polymerization from taking place (see ESI, $\uparrow$ 
blank experiments), as no polymer growth was detected. Concomitantly, this proves that the polymerization only occurs from initiators grafted on the surfaces.

The polymerization kinetics were studied for the full range of monomers employed to graft polymer brushes (see Scheme 1) using DMSO as the solvent for all monomers except EHMA and IBMA. In these two cases the polymerization took place in DMSO/toluene $1: 2$ to achieve monomer miscibility. All polymerization solutions were exposed to irradiation from $2.5 \mathrm{~min}$ to $30 \mathrm{~min}$. The evolution of the obtained thickness is presented in Fig. 3. During that time the rate of growth was close to constant for each monomer. The observed linear growth implies that the propagation rate is constant, eviden- cing the (near) absence of termination processes during the polymerization and the preservation of the growing polymerization centres. The SET-LRP polymerization of SMA was performed for the first time. It was considerably slower than the other methacrylates. This was in agreement with previous reports showing less than full conversion and low rates even at high temperatures (65 and $\left.85^{\circ} \mathrm{C}\right) .{ }^{74-76}$ It is interesting to note that photoinduced SET-LRP has also been successfully applied to acrylate ${ }^{41}$ and methacrylamide ${ }^{65}$ monomers, achieving in both cases linear polymerization kinetics. The application of this photoinduced SET-LRP procedure to methacrylates is also effective to achieve a high thickness in short polymerization times with a low catalyst concentration.
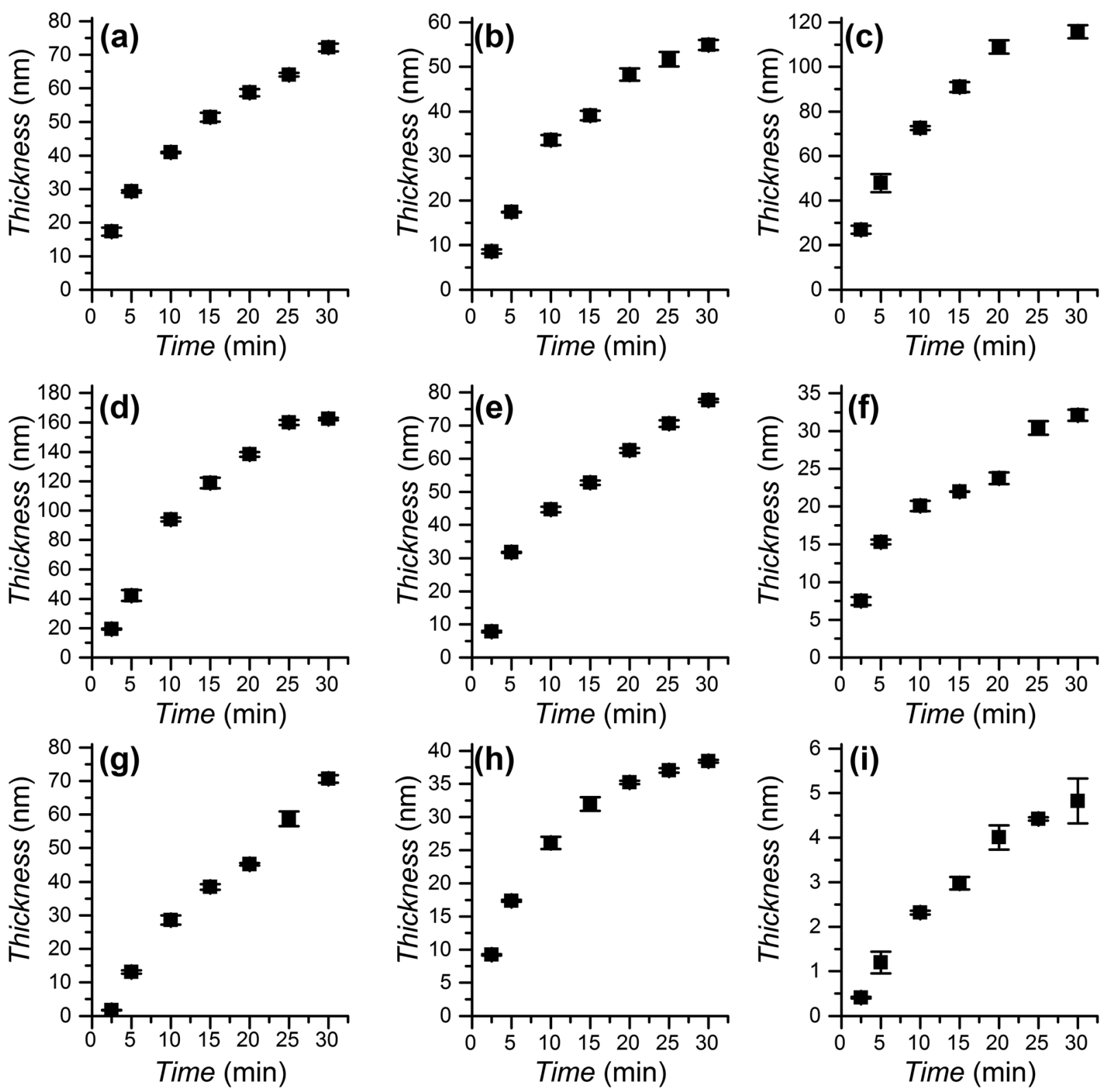

Fig. 3 Dry ellipsometric thickness of polymethacrylate brushes: (a) HEMA, (b) HPM, (c) MeOEGMA, (d) tBMA, (e) nBMA, (f) MMA, (g) EHMA, (h) IBMA, and (i) SMA. Conditions: [Monomer] $=1.68 \mathrm{M},\left[\mathrm{CuBr}_{2}\right]=166 \mu \mathrm{M},\left[\mathrm{Me}_{6} \mathrm{TREN}\right]=995 \mu \mathrm{M}$. Solvents: (a) $-(\mathrm{f})$, (i) DMSO, (g), (h) DMSO/toluene 1:2. 


\section{Livingness}

The presence of the dormant species on the polymer chain ends, able to be re-initiated, was demonstrated by performing re-initiation experiments and confirming the ability to synthesize diblock copolymer brushes. EHMA was selected as the bottom block to be used as a macroinitiator, prepared by immersing the initiator-coated substrates in the polymerization solution and irradiating under the same conditions used to study the polymerization kinetics. ${ }^{41,65}$ Using these poly (EHMA) brushes as substrates, the polymerization was reinitiated for simple chain extension with EHMA or alternatively, a second block of poly(MeOEGMA). For this, MeOEGMA was chosen due to the significant difference with poly(EHMA) in the expected composition ratios that can be observed by XPS, specifically in the $\mathrm{C} 1 \mathrm{~s}$ region between $\mathrm{C}-\mathrm{O}$ and $\mathrm{C}^{*}-\mathrm{O}-$ $(\mathrm{C}=\mathrm{O})$ and $\mathrm{C}-\mathrm{C}, \mathrm{C}-\mathrm{H}$ and $\left(\mathrm{C}^{*}=\mathrm{O}\right) \mathrm{O}$.

For the re-initiation experiment, the first poly(EHMA) brush was polymerized for $10 \mathrm{~min}$ in DMSO/toluene, ([EHMA] = $1.68 \mathrm{M},\left[\mathrm{CuBr}_{2}\right]=166 \mu \mathrm{M},\left[\mathrm{Me}_{6}\right.$ TREN $\left.]=995 \mu \mathrm{M}\right)$ reaching a thickness which corresponds well to the polymerization kinetics. Subsequently, the same sample was immersed in a freshly prepared polymerization solution containing EHMA as the monomer and irradiated for a further $20 \mathrm{~min}$. The total polymer layer thickness shows that the growth after reinitiation proceeded at the same rate as on a continuously irradiated sample (Fig. 4a). The ability of the polymerization to be re-initiated indicates the preservation of the dormant polymerization centers after the first polymerization step.

Additionally, a diblock copolymer was prepared by re-initiating the substrates coated with poly(EHMA) of $(52.2 \pm 0.4) \mathrm{nm}$ thickness with MeOEGMA ([MeOEGMA $]=1.68 \mathrm{M},\left[\mathrm{CuBr}_{2}\right]=$ $166 \mu \mathrm{M},\left[\mathrm{Me}_{6}\right.$ TREN $\left.]=995 \mu \mathrm{M}\right)$ to reach a total thickness of $(150.4 \pm 4.0) \mathrm{nm}$. This corresponds to a thickness of $98.2 \mathrm{~nm}$ for the second block. The changes in the chemical compo- sition of the diblock copolymer layer were confirmed by depth profiling performed by XPS, i.e. acquiring spectra after increasing the etching time with $\mathrm{Ar}^{+}$clusters. Fig. $4 \mathrm{~b}$ shows the evolution of the $\mathrm{C} 1 \mathrm{~s}$ region of the XPS spectrum of poly(EHMA- $b$ MeOEGMA) with increasing etch depth. The uppermost 50-nm-thick brush layer shows a clear predominance of the peak at $(286.6 \pm 0.1)$ eV originating from the $\underline{\mathrm{C}}-\mathrm{O}-\mathrm{C}$ contributions of MeOEGMA. The intensity of this peak rapidly decreases throughout the following $40 \mathrm{~nm}$ in the direction of the substrate. The 60-nm-thick bottom layer is dominated by the $(\underline{\mathrm{C}}-\mathrm{C}, \underline{\mathrm{C}}-\mathrm{H})$ contributions at $285.0 \mathrm{eV}$ of the EHMA block. A detailed analysis by deconvolution of the contributions constituting the $\mathrm{C}$ 1s envelope (Fig. 4c) further proved the intuitive observation presented in the waterfall graph. Based on the measured ratios between the components within the high resolution $\mathrm{C}$ 1s XPS spectra of poly(MeOEGMA) and poly (EHMA) homopolymers (see the ESI, Table ST1 $\dagger$ ) and the measured depth evolution of the $(\underline{\mathrm{C}}-\mathrm{O}-\mathrm{C}, \underline{\mathrm{C}}-\mathrm{O}-(\mathrm{C}=\mathrm{O})):(\underline{\mathrm{C}}-\mathrm{C}$, $\underline{\mathrm{C}}-\mathrm{H}),(\underline{\mathrm{C}}-\mathrm{C}, \underline{\mathrm{C}}-\mathrm{H}):(\mathrm{O}-\underline{\mathrm{C}}=\mathrm{O})$ and $\underline{\mathrm{C}}^{*}-(\mathrm{C}=\mathrm{O})-\mathrm{O}: \mathrm{O}-\underline{\mathrm{C}}=\mathrm{O}$ ratios (see the ESI, Fig. SF6 ${ }^{\dagger}$ ) we have approximated the average atomic composition of the poly(EHMA- $b$-MeOEGMA) brushes over etch depth (Fig. 4d). As can be seen from the compositional profile, the top layer is almost exclusively composed of MeOEGMA (concentration of more than 90 atomic\%), whereas the bottom layer, close to the substrate, has a clear predominance of EHMA units (concentration of more than 85 atomic\%). These results clearly confirm not only the successful chain extension of poly(EHMA) by MeOEGMA, but also prove the block copolymer structure of the end-tethered poly(EHMA- $b$ MeOEGMA) brushes.

\section{Spatial control}

Since the polymerization is photo-triggered (see the ESI, $\uparrow$ blank experiment), a simple restriction of the irradiation area (a)

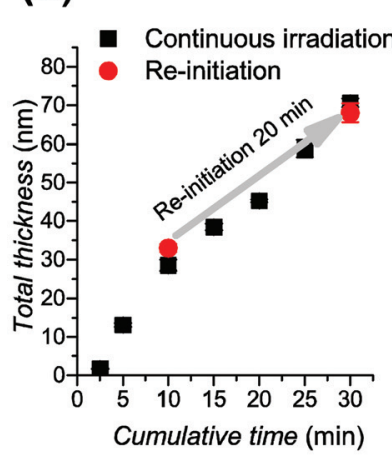

(b)

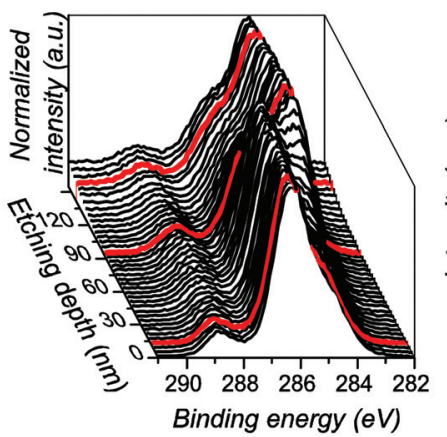

(c)

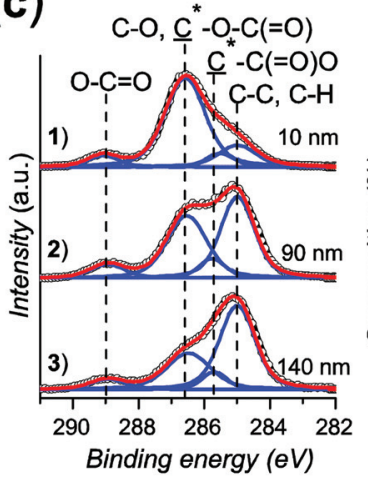

(d)

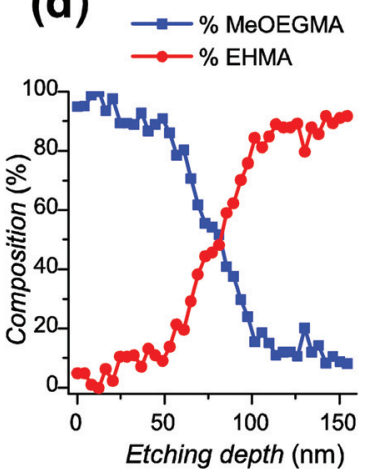

Fig. 4 (a) Dry ellipsometric thickness of poly(EHMA) before and after re-initiation of the polymerization, carried out in DMSO/toluene (1:2) (red dots). $[E H M A]=1.68 \mathrm{M},\left[\mathrm{CuBr}_{2}\right]=166 \mu \mathrm{M},\left[\mathrm{Me}_{6} \mathrm{TREN}\right]=995 \mu \mathrm{M}$. Initial irradiation for 10 min yielded poly(EHMA) brushes of (32.9 \pm 1.0$)$ nm thickness, which were used as macroinitiators for re-initiation of the polymerization (for an additional 20 min) to yield poly(EHMA) brushes of $(68.1 \pm 2.5) \mathrm{nm}$ thickness. The polymerization kinetics with continuous irradiation are shown for comparison (black squares). (b)-(d) XPS depth profile of poly(EHMA- $b-$ MeOEGMA). (b) Evolution of the C 1s XPS spectrum with etch depth. (c) Deconvolution of representative $C$ 1s XPS spectra at three etch depths. (d) Approximate ratio of MeOEGMA (blue squares) and EHMA (red dots) monomer units in poly(EHMA- $b$-MeOEGMA) brushes over etch depth. The total thickness of the poly(EHMA-b-MeOEGMA) was $(150.4 \pm 4.0) \mathrm{nm}$. 

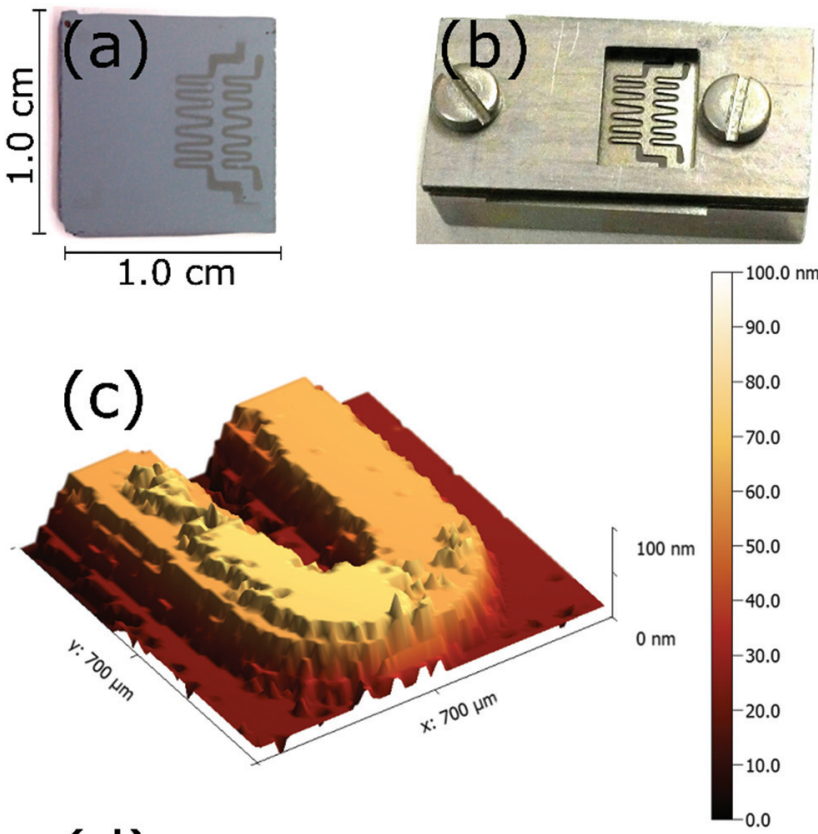

(d)

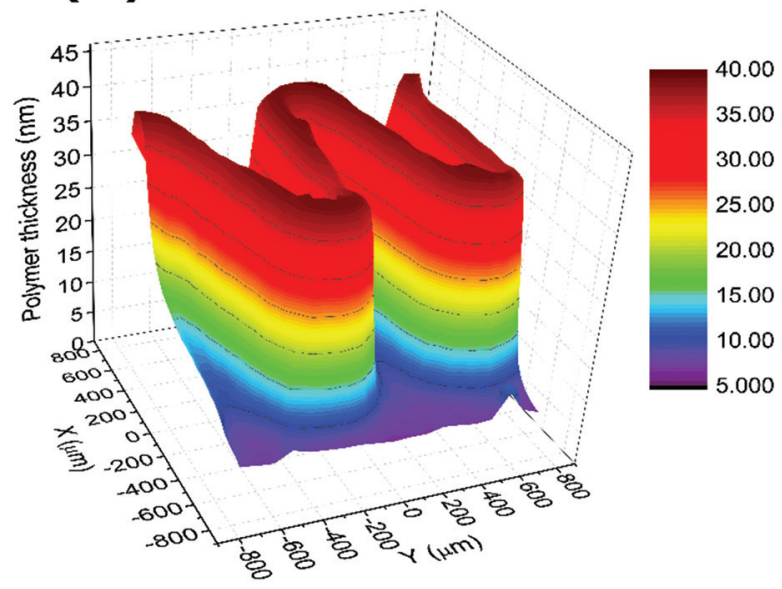

Fig. 5 Patterning of poly(DMAEMA) brushes using photoinduced SET-LRP. (a) Optical image of the pattern, (b) picture of the sample holder featuring the shadow mask used, (c) profilometry of a small area of the pattern and (d) ellipsometric mapping of the pattern. Conditions: $[\mathrm{DMAEMA}]=1.68 \mathrm{M},\left[\mathrm{CuBr}_{2}\right]=166 \mu \mathrm{M}(7.7 \mathrm{ppm}),\left[\mathrm{Me}_{6} \mathrm{TREN}\right]=995 \mu \mathrm{M}$, DMSO.

on the substrate using a shadow mask (Fig. $5 \mathrm{~b}$ ) can be employed to confine the growth of the brushes. After 10 min of polymerization of DMAEMA, the pattern obtained on the surface was visible to the naked eye. Stylus profilometry (Fig. 5c) and ellipsometric mapping (Fig. 5d) confirmed the successful patterning on the surface. Both techniques yield the same thickness in examined areas, which corresponds to the expected value from the studied polymerization kinetics of this monomer.

\section{Antifouling properties}

One of the main problems in label-free affinity biosensing is the inability to discriminate between signals arising from the specific response to the binding of the analyte and the nonspecific response to the deposition of other compounds from the tested media. ${ }^{7,77}$ Therefore, it is critical to control the interactions occurring at the interface in applications involving surfaces making contact with biological media. Poly(MeOEGMA) has been widely studied for its ability to suppress fouling. ${ }^{6,67,69,78}$

As photoinduced SET-LRP provides a practical way to create patterned surfaces, we studied the ability of the brushes grown by this technique to reduce protein fouling from model solutions in buffer as well as real biological media. The antifouling properties for the obtained poly(MeOEGMA) brushes were studied by surface plasmon resonance (SPR). The optimum dry thickness previously reported for poly(MeOEGMA) brushes to reach the maximum resistance to protein fouling is around $30 \mathrm{~nm} .{ }^{6}$ Polymer brushes of $12 \mathrm{~nm}, 28 \mathrm{~nm}$ and $51 \mathrm{~nm}$ thickness were grown by photoinduced SET-LRP in less than $5 \mathrm{~min}$, from gold-coated glass substrates (SPR sensor chips) modified with a SAM of $\omega$-mercaptoundecyl bromoisobutyrate. The adsorption from model solutions of the main plasma proteins, human serum albumin (HSA) and fibrinogen (Fbg), as well as from undiluted human blood plasma (BP) and fetal bovine serum (FBS) was studied. The brushes were brought into contact with the solutions for $15 \mathrm{~min}$. No fouling could be detected for HSA and Fbg on any of the poly(MeOEGMA) brushes evaluated. For more challenging complex media FBS and BP the fouling was $1.95 \mathrm{ng} \mathrm{cm}^{-2}$ and $16.2 \mathrm{ng} \mathrm{cm}^{-2}$ respectively for the 28-nm-thick brushes (Fig. 6 and Table ST4 in the ESI†). The thinner $12 \mathrm{~nm}$-thick poly(MeOEGMA) brushes showed diminished antifouling performance in accordance with previous results, at $4.35 \mathrm{ng} \mathrm{cm} \mathrm{cm}^{-2}$ and $28.6 \mathrm{ng} \mathrm{cm}^{-2}$ for

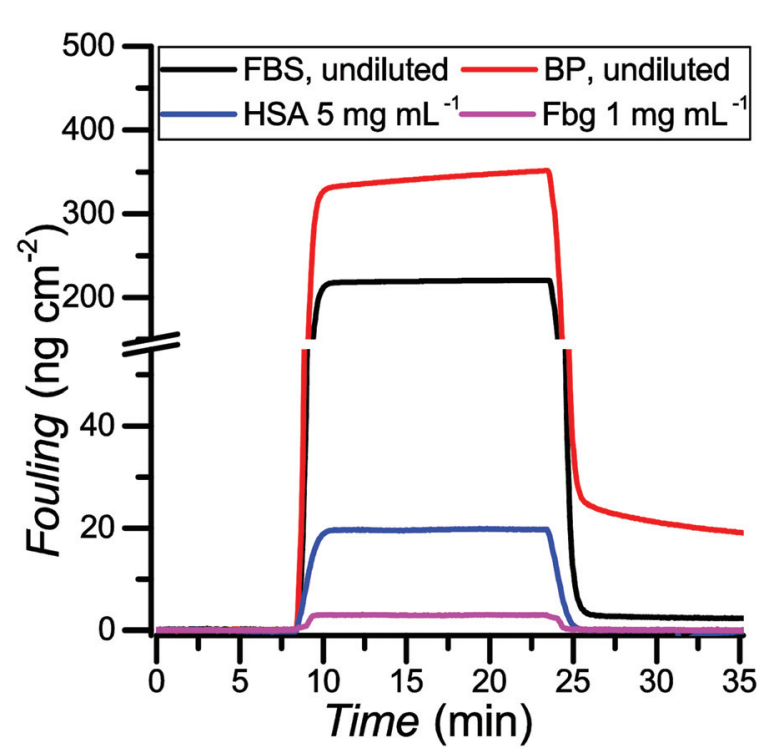

Fig. 6 Protein fouling measured by SPR on a gold SPR chip coated with poly(MeOEGMA) brushes $(28 \mathrm{~nm})$. Black: fetal bovine serum (FBS, undiluted); red: undiluted blood plasma (BP, undiluted); blue: human

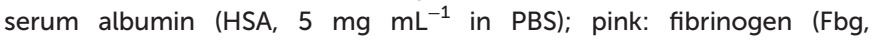
$1 \mathrm{mg} \mathrm{mL}^{-1}$ in PBS). 
FBS and BP, respectively (Table ST4 in the ESI $\dagger$ ). ${ }^{79}$ The brushes of $51 \mathrm{~nm}$ thickness performed similarly as those of $28 \mathrm{~nm}$ thickness (fouling of $2.5 \mathrm{ng} \mathrm{cm} \mathrm{cm}^{-2}$ and $16.3 \mathrm{ng} \mathrm{cm} \mathrm{cm}^{-2}$ for FBS and BP respectively). The obtained surfaces of optimum thickness $(28 \mathrm{~nm})$ reduced $95 \%$ of the fouling in comparison with the fouling on a bare gold surface. The antifouling properties displayed by the poly(MeOEGMA) brushes achieved by the present technique are on the same level as those of brushes prepared from the same monomer by other previously reported polymerization protocols. $^{6}$

\section{Conclusions}

The successful surface-confined photoinduced SET-LRP of a wide range of methacrylate monomers was achieved with only small amounts of a copper catalyst. In particular, the surface grafting of solketal methacrylate is reported for the first time. The living nature of polymerization was demonstrated via formation of a diblock copolymer brush. Successful spatial control over polymerization of methacrylate monomers was also demonstrated. The antifouling properties of poly[oligo (ethylene glycol) methyl ether methacrylate] brushes, critical for biomedical devices and biosensing, were demonstrated by surface plasmon resonance.

These features make this procedure highly promising for advanced applications requiring precise control over the properties of surfaces as well as the ability to create patterns.

\section{Experimental}

\section{Materials}

Oligo(ethylene glycol) methyl ether methacrylate $\left(M_{\mathrm{n}}=300\right.$ g $\mathrm{mol}^{-1}$, MeOEGMA), 2-hydroxyethyl methacrylate ( $\geq 99 \%$, HEMA), $t$-butyl methacrylate (98\%, $t$ BMA), $n$-butyl methacrylate (99\%, nBMA), methyl methacrylate (99\%, MMA), 2-ethylhexyl methacrylate (98\%, EHMA), 2-(dimethylamino)ethyl methacrylate (98\%, DMAEMA), solketal methacrylate (50 wt\% in dichloromethane, SMA), isobornyl methacrylate (98.5\%, IBMA), $\mathrm{CuBr}_{2}$ (99.999\% trace metal basis), and tris[2-(dimethylamino) ethyl]amine (97\%, $\mathrm{Me}_{6}$ TREN) were obtained from SigmaAldrich, Czech Republic. 2-Hydroxypropyl methacrylate, toluene (extra-dry over molecular sieves, 99.85\%) and dry dimethyl sulfoxide (extra-dry over molecular sieves 99.7\%, DMSO) were purchased from Acros, Czech Republic. Ethanol (99.8\%, EtOH), acetone (99.5\%), tetrahydrofuran (99.5\%, THF), toluene (99\%), and DMSO (99\%) were purchased from LachNer, Czech Republic. Deionized water was obtained from a Milli-Q system (Merck-Millipore, Czech Republic). Silicon wafers were purchased from Siegert Wafer GmbH, Germany. 11-(Trichlorosilyl)undecyl 2-bromo-2-methylpropanoate ${ }^{9}$ and $\omega$-mercaptoundecyl bromoisobutyrate ${ }^{80}$ were synthesized according to procedures published earlier. Human blood plasma (mix from 5 donors) was provided by the Institute of Hematology and Blood Transfusion, Czech Republic. Fetal bovine serum, fibrinogen and human serum albumin were purchased from Sigma-Aldrich, Czech Republic.

\section{Self-assembled monolayer of initiator}

Silicon wafer substrates $\left(1 \times 1 \mathrm{~cm}^{2}\right)$ were rinsed twice with EtOH and deionized water. All substrates were exposed to air plasma for $20 \mathrm{~min}$ to generate silanol groups on the surface. The freshly activated surfaces were immediately immersed in a $1 \mathrm{mg} \mathrm{mL} \mathrm{m}^{-1}$ solution of 11-(trichlorosilyl)undecyl 2-bromo-2methylpropanoate in dry toluene. The silanization of the substrates to form the self-assembled monolayer was allowed to proceed for $3 \mathrm{~h}$ at room temperature in a dry environment. The substrates were subsequently rinsed with toluene, acetone, EtOH, and deionized water and blow-dried with $\mathrm{N}_{2}$.

The SPR chips (gold-coated glass) and gold-coated Si-wafer chips were cleaned by rinsing twice with EtOH and deionized water, blow dried with $\mathrm{N}_{2}$, and cleaned in a UV/Ozone cleaner (Jelight) for $20 \mathrm{~min}$. Directly after cleaning, the chips were immersed in a $1 \mathrm{mM}$ solution of $\omega$-mercaptoundecyl bromoisobutyrate in $\mathrm{EtOH}$ and kept overnight in the dark at room temperature. Subsequently, they were rinsed twice with EtOH and deionized water and blow-dried with $\mathrm{N}_{2}$.

\section{Photoinduced SET-LRP of methacrylates}

A stock solution (S) of $\mathrm{CuBr}_{2}(3.9 \mathrm{mM})$ and $\mathrm{Me}_{6}$ TREN (23.4 $\mathrm{mM}$ ) was freshly prepared in dry DMSO. An aliquot of the stock solution $\mathrm{S}(273 \mu \mathrm{L})$ was transferred to a roundbottom flask containing dry DMSO $(3.15 \mathrm{~mL})$ to give the solution A. In another round-bottom flask, a solution of methacrylate monomer $(10.8 \mathrm{mmol})$ in DMSO $(3.00 \mathrm{~mL})$ was prepared (solution B). Solutions A and B were degassed by bubbling Ar for $60 \mathrm{~min}$ while stirring and kept in the dark by wrapping them in Al-foil. Subsequently, solution A was transferred using a gas-tight syringe under Ar protection to solution B. The combined polymerization solution $\mathrm{C}$ was stirred and transferred to individual crimped vials containing the initiator-coated $\mathrm{Si}$ wafer substrates, which had been previously degassed by purging with Ar for 15 min. The polymerization was conducted by irradiating the vials inside a UV-reactor, consisting of a nail-curing device (four $9 \mathrm{~W}$ lamps, $\lambda_{\max }=365 \mathrm{~nm}$ ) placed on top of a shaker plate $\left(90 \mathrm{~min}^{-1}\right)$ and kept at room temperature. After irradiation for a preset amount of time the vials were removed from the reactor, quickly opened, and filled with DMSO to quench the polymerization. The samples were removed from the solution and rinsed with DMSO, acetone, $\mathrm{EtOH}$, and deionized water in the case of hydrophilic monomers, or DMSO, acetone, THF, and EtOH for hydrophobic monomers, and dried by blowing with $\mathrm{N}_{2}$.

For the polymerization of EHMA and IBMA, the same procedure was employed but using a 1:2 mixture of dry DMSO/ toluene as the solvent instead of pure DMSO. For the polymerization of methyl methacrylate, a volume of stock solution $\mathrm{S}$ $(273 \mu \mathrm{L})$ was transferred to a round bottom flask containing DMSO $(6.15 \mathrm{~mL})$ to form solution A, while the neat monomer was degassed separately by bubbling Ar for $1 \mathrm{~h}$. After degas- 
sing, the appropriate amount of monomer $(10.8 \mathrm{mmol}$, $1.15 \mathrm{~mL}$ ) was transferred to solution A by using a gas-tight syringe under Ar protection to obtain solution C. The polymerization procedure was continued in the same way as described above.

\section{Patterning of DMAEMA}

The pattern of DMAEMA was prepared by the photoinduced SET-LRP procedure in DMSO ([DMAEMA] $=1.68 \mathrm{M},\left[\mathrm{CuBr}_{2}\right]=$ $166 \mu \mathrm{M}$, and $\left[\mathrm{Me}_{6}\right.$ TREN $\left.]=995 \mu \mathrm{M}\right)$ as was described above. The Si wafer was mounted in a shadow mask holder and covered with a shadow mask (Fig. 5b). The polymerization was conducted by irradiating the vial inside the UV-reactor for $10 \mathrm{~min}$. The sample was removed from the shadow mask holder, rinsed with DMSO, acetone, THF, and EtOH, and dried by blowing with $\mathrm{N}_{2}$.

\section{Re-initiation of EHMA}

The polymer brushes of EHMA were prepared by the photoinduced SET-LRP procedure in DMSO/toluene 1:2 ([EHMA] = $1.68 \mathrm{M},\left[\mathrm{CuBr}_{2}\right]=166 \mu \mathrm{M}$, and $\left[\mathrm{Me}_{6}\right.$ TREN $\left.]=995 \mu \mathrm{M}\right)$. After UV irradiation for $10 \mathrm{~min}$, the polymerization was stopped, the samples were rinsed with DMSO, acetone, THF, and $\mathrm{EtOH}$, and blow-dried with $\mathrm{N}_{2}$. The obtained surfaces were characterized by ellipsometry. Subsequently, these surfaces were immersed in a freshly prepared polymerization solution of EHMA and irradiated for an additional $20 \mathrm{~min}$. The samples were rinsed with solvents and dried with $\mathrm{N}_{2}$. The thickness of the samples was measured by ellipsometry.

\section{Grafting of poly(EHMA- $b$-MeOEGMA)}

The first block of poly(EHMA) brushes was prepared by photoinduced SET-LRP in DMSO/toluene 1:2 as described above. The polymerization proceeded under UV-irradiation, and subsequently the samples were removed from the solution and rinsed with DMSO, acetone, THF, and $\mathrm{EtOH}$, and dried by blowing with $\mathrm{N}_{2}$.

The second block of poly(MeOEGMA) was prepared by photoinduced SET-LRP in DMSO ([MeOEGMA $]=1.68 \mathrm{M}$, $\left[\mathrm{CuBr}_{2}\right]=166 \mu \mathrm{M}$, and $\left[\mathrm{Me}_{6}\right.$ TREN $\left.]=995 \mu \mathrm{M}\right)$ as described above, using the substrates with a grafted first block of poly (EHMA) as macroinitiators. The polymerization was conducted by irradiating the vials inside the UV-reactor for $25 \mathrm{~min}$. The samples were rinsed with DMSO, acetone, EtOH, and deionized water, and dried by blowing with $\mathrm{N}_{2}$.

\section{Surface characterization}

Spectroscopic ellipsometry. J.A. Woollam M-2000X Spectroscopic Ellipsometer was used to measure the dry thickness of the polymer brushes to study the kinetics of the polymerization. Ellipsometric data were obtained in air at room temperature in the wavelength range $\lambda=245-1000 \mathrm{~nm}$ at angles of incidence (AOI) of 60,65 , and $70^{\circ}$. The data were fitted with CompleteEASE software using a multilayer model. The thicknesses are reported for 3 points on the surface as mean \pm standard deviation. For the thickness mapping by ellipsometry of the photo-patterned samples, data were recorded in the same wavelength range at an AOI of $50^{\circ}$ and fitted for each point, on a $1.5 \mathrm{~mm} \times 1.5 \mathrm{~mm}$ area covering the region of interest. The sample was scanned in a hexagonal grid (pixel distance $50 \mu \mathrm{m}$ ) employing a motorized translator stage.

X-ray photoelectron spectroscopy (XPS). XPS measurements

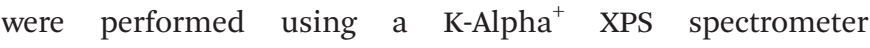
(ThermoFisher Scientific, UK) operating at a base pressure of $\left(1.0 \times 10^{-7}\right) \mathrm{Pa}$. The data acquisition and processing were performed using the Thermo Avantage software. All samples were analyzed using microfocused, monochromated $\mathrm{Al} \mathrm{K} \alpha$ X-ray radiation (400 $\mu \mathrm{m}$ spot size) with a pass energy of $200 \mathrm{eV}$ for survey and $20 \mathrm{eV}$ for high-energy resolution spectra. The angle of incidence was $60^{\circ}$ with respect to the sample surface normal and the emission angle was along the surface normal. The K-Alpha charge dual compensation system was employed during analysis, using electrons and low-energy argon ions to prevent any localized charge build-up. XPS depth profiling was performed utilizing the MAGCIS source operated in small cluster ion mode (1000 Ar atoms per cluster) at $6000 \mathrm{eV}$. Each sputtering cycle lasted $65 \mathrm{~s}$ and an area of $(5 \times 3) \mathrm{mm}^{2}$ was rastered. The etching rate was determined to be $0.07 \mathrm{~nm} \mathrm{~s}^{-1}$. XPS spectra acquired in between etch cycles allowed qualitative and quantitative determination of the moieties present in the block-copolymer layer.

The obtained high resolution spectra were fitted/deconvoluted with Voigt profiles (binding energy uncertainty: $\pm 0.2 \mathrm{eV}$ ). The analyzer transmission function, Scofield sensitivity factors, and effective attenuation lengths (EALs) for photoelectrons were applied for quantification. EALs were calculated using the standard TPP-2M formalism. ${ }^{81,82}$ All spectra were referenced to the $\mathrm{C} 1 \mathrm{~s}$ peak attributed to $\mathrm{C}-\mathrm{C}, \mathrm{C}-\mathrm{H}$ at $285.0 \mathrm{eV}$ binding energy, which was controlled by means of the wellknown photoelectron peaks of metallic $\mathrm{Cu}, \mathrm{Ag}$, and $\mathrm{Au}$.

The reconstruction of the average atomic concentration profile of MeOEGMA $(\bar{x})$ and 2-EHMA $(\bar{y}=1-\bar{x})$ monomers in the poly(EHMA- $b$-MeOEGMA) brush was performed on basis of the measured individual component ratios in the high resolution C 1s XPS spectra:

$$
\begin{gathered}
a=\frac{(\underline{\mathrm{C}}-\mathrm{O}-\mathrm{C}, \underline{\mathrm{C}}-\mathrm{O}-(\mathrm{C}=\mathrm{O}))}{(\underline{\mathrm{C}}-\mathrm{C}, \underline{\mathrm{C}}-\mathrm{H})} ; \\
b=\frac{(\underline{\mathrm{C}}-\mathrm{C}, \underline{\mathrm{C}}-\mathrm{H})}{(\mathrm{O}-\underline{\mathrm{C}}=\mathrm{O})} ; \\
c=\frac{\left(\underline{\mathrm{C}}^{*}-(\mathrm{C}=\mathrm{O})-\mathrm{O}\right)}{(\mathrm{O}-\underline{\mathrm{C}}=\mathrm{O})} ;
\end{gathered}
$$

between the components of poly(MeOEGMA) and poly(EHMA) homopolymers and the measured depth evolution of the respective ratios in the block copolymer utilizing the equation:

$$
\begin{aligned}
{[a, b, c]_{\text {poly(EHMA- } b \text {-MeOEGMA })}=} & \bar{x} \times[a, b, c]_{\text {poly(MeOEGMA })} \\
& +\bar{y} \times[a, b, c]_{\text {poly(MeOEGMA-EHMA })} .
\end{aligned}
$$

The experimental uncertainties in the quantitative analysis of XPS are estimated to be below $7 \%$. The value covers the 
overall uncertainties of the method that are typically introduced by the background subtraction.

Dynamic water contact angle. The sessile drop method was used to measure the dynamic water contact angle and studied the wettability of the surfaces, with a DataPhysics OCA 20 instrument. A $5 \mu \mathrm{L}$ drop was placed on the surface and its volume was increased up to $15 \mu \mathrm{L}$ and decreased back to $5 \mu \mathrm{L}$ at a flow rate of $0.2 \mu \mathrm{L} \mathrm{s}^{-1}$. The drop profile was fitted with a circular algorithm, from which the advancing and receding contact angles were obtained.

Atomic force microscopy (AFM). AFM images were obtained as topographical scans in tapping mode in air by using a Multimode Atomic Force Microscope NanoScope IIIa (Digital Instruments), using silicon probes OTESPA-R3 (Bruker) with a nominal spring constant of $26 \mathrm{~N} \mathrm{~m}^{-1}$ and a tip radius of $7 \mathrm{~nm}$. Areas of $5 \times 5 \mu^{2}(512 \times 512$ pixels $)$ were scanned at a rate of $1 \mathrm{~Hz}$. Gwyddion software was used to analyze the scans.

Stylus profilometry. Stylus profilometry was accomplished using a Tencor P-10 Surface Profiler (Texas, USA). Topography scans over areas of $(600 \times 700) \mu \mathrm{m}^{2}$ were obtained at a speed of $20 \mu \mathrm{m} \mathrm{s}^{-1}$ and a sampling rate of $100 \mathrm{~Hz}$. The stylus force was set at $0.01 \mathrm{~N}$.

Surface plasmon resonance (SPR). The antifouling properties of the obtained MeOEGMA polymer brushes were studied by SPR with a custom-made SPR instrument based on the Kretschmann geometry of the attenuated total reflection method and spectral interrogation of the SPR conditions that was purchased from the Institute of Photonics and Electronics, ASCR v.v.i., Czech Republic. The temperature during the measurement was kept at $25{ }^{\circ} \mathrm{C}$. The shift in the resonant wavelength (sensor response, $\Delta \lambda_{\text {res }}$ ) was obtained as the difference between the baselines in phosphate buffered saline (PBS) before and after the injection of the tested solutions: human serum albumin, fibrinogen, fetal bovine serum, and human blood plasma. During the experiment, the flow rate of the solutions in each chamber of the flow cell was kept at $25 \mu \mathrm{L} \mathrm{min}{ }^{-1}$. The increase of mass deposited on the surface was calculated from the sensor response. According to a calibration made by Fourier-transform infrared grazing angle specular reflectance, a shift $\Delta \lambda_{\text {res }}=1 \mathrm{~nm}$ corresponds to a change in the deposited protein mass of $15 \mathrm{ng} \mathrm{cm}{ }^{-2}$.

\section{Acknowledgements}

This work was partially performed at the Center for Chemical Polymer Technology (CPT) under the support of the EU and the federal state of North Rhine-Westphalia (Grant EFRE 3000883 02). The work was also supported by the Grant Agency of the Czech Republic (GACR) under contract no. 15-09368Y and by OPPK CZ.2.16/3.1.00/21545. Financial support by the National Science Foundation (DMR-1066116 and DMR-1120901), the Humboldt Foundation and the P. Roy Vagelos Chair at Penn (all to VP) is gratefully acknowledged.

\section{Notes and references}

1 B. Zhao and W. J. Brittain, Prog. Polym. Sci., 2000, 25, 677710.

2 S. T. Milner, Science, 1991, 251, 905-914.

3 F. Denes, V. Percec, M. Totolin and J. P. Kennedy, Polym. Bull., 1980, 2, 499-504.

4 S. Minko, J. Macromol. Sci., Polym. Rev., 2006, 46, 397-420.

5 M. A. C. Stuart, W. T. S. Huck, J. Genzer, M. Muller, C. Ober, M. Stamm, G. B. Sukhorukov, I. Szleifer, V. V. Tsukruk, M. Urban, F. Winnik, S. Zauscher, I. Luzinov and S. Minko, Nat. Mater., 2010, 9, 101-113.

6 C. Rodriguez-Emmenegger, E. Brynda, T. Riedel, M. Houska, V. Subr, A. B. Alles, E. Hasan, J. E. Gautrot and W. T. Huck, Macromol. Rapid Commun., 2011, 32, 952957.

7 C. Rodriguez-Emmenegger, E. Brynda, T. Riedel, Z. Sedlakova, M. Houska and A. B. Alles, Langmuir, 2009, 25, 6328-6333.

8 M. Krishnamoorthy, S. Hakobyan, M. Ramstedt and J. E. Gautrot, Chem. Rev., 2014, 114, 10976-11026.

9 C. Rodriguez-Emmenegger, S. Janel, A. de los Santos Pereira, M. Bruns and F. Lafont, Polym. Chem., 2015, 6, 5740-5751.

10 A. de los Santos Pereira, T. Riedel, E. Brynda and C. Rodriguez-Emmenegger, Sens. Actuators, B, 2014, 202, 1313-1321.

11 C. Rodriguez-Emmenegger, M. Houska, A. B. Alles and E. Brynda, Macromol. Biosci., 2012, 12, 1413-1422.

12 A. de los Santos Pereira, C. Rodriguez-Emmenegger, F. Surman, T. Riedel, A. B. Alles and E. Brynda, RSC Adv., 2014, 4, 2318.

13 T. Riedel, C. Rodriguez-Emmenegger, A. de los Santos Pereira, A. Bědajánková, P. Jinoch, P. M. Boltovets and E. Brynda, Biosens. Bioelectron., 2014, 55, 278-284.

14 T. Riedel, F. Surman, S. Hageneder, O. Pop-Georgievski, C. Noehammer, M. Hofner, E. Brynda, C. RodriguezEmmenegger and J. Dostalek, Biosens. Bioelectron., 2016, 85, 272-279.

15 P. Jain, G. L. Baker and M. L. Bruening, Annu. Rev. Anal. Chem., 2009, 2, 387-408.

16 O. Azzaroni, J. Polym. Sci., Part A: Polym. Chem., 2012, 50, 3225-3258.

17 R. Barbey, L. Lavanant, D. Paripovic, N. Schüwer, C. Sugnaux, S. Tugulu and H.-A. Klok, Chem. Rev., 2009, 109, 5437-5527.

18 R. Advincula, in Surface-Initiated Polymerization I, 2006, vol. 197, pp. 107-136.

19 W. J. Brittain and S. Minko, J. Polym. Sci., Part A: Polym. Chem., 2007, 45, 3505-3512.

20 S. Edmondson, V. L. Osborne and W. T. S. Huck, Chem. Soc. Rev., 2004, 33, 14-22.

21 C. J. Fristrup, K. Jankova and S. Hvilsted, Soft Matter, 2009, $5,4623-4634$.

22 U. Yildiz, B. Hazer and K. Tauer, Polym. Chem., 2012, 3, 1107. 
23 M. Zamfir, C. Rodriguez-Emmenegger, S. Bauer, L. Barner, A. Rosenhahn and C. Barner-Kowollik, J. Mater. Chem. B, 2013, 1, 6027-6034.

24 K. J. Bian and M. F. Cunningham, Polymer, 2006, 47, 57445753.

25 L. Ghannam, J. Parvole, G. Laruelle, J. Francois and L. Billon, Polym. Int., 2006, 55, 1199-1207.

26 Z. Chen, Q. Yang, K. Peng and Y. Guo, J. Appl. Polym. Sci., 2011, 119, 3582-3590.

27 S. B. Rahane, A. T. Metters and S. M. Kilbey, Macromolecules, 2006, 39, 8987-8991.

28 J. Ma, S. Luan, L. Song, J. Jin, S. Yuan, S. Yan, H. Yang, H. Shi and J. Yin, ACS Appl. Mater. Interfaces, 2014, 6, 19711978.

29 V. Percec, A. V. Popov, E. Ramirez-Castillo, M. Monteiro, B. Barboiu, O. Weichold, A. D. Asandei and C. M. Mitchell, J. Am. Chem. Soc., 2002, 124, 4940-4941.

30 V. Percec, A. V. Popov, E. Ramirez-Castillo and O. Weichold, J. Polym. Sci., Part A: Polym. Chem., 2003, 41, 3283-3299.

31 N. Zhang, S. R. Samanta, B. M. Rosen and V. Percec, Chem. Rev., 2014, 114, 5848-5958.

32 V. Percec, T. Guliashvili, J. S. Ladislaw, A. Wistrand, A. Stjerndahl, M. J. Sienkowska, M. J. Monteiro and S. Sahoo, J. Am. Chem. Soc., 2006, 128, 14156-14165.

33 G. Lligadas and V. Percec, J. Polym. Sci., Part A: Polym. Chem., 2007, 45, 4684-4695.

34 N. H. Nguyen, C. Rodriguez-Emmenegger, E. Brynda, Z. Sedlakova and V. Percec, Polym. Chem., 2013, 4, 24242427.

35 A. H. Soeriyadi, C. Boyer, F. Nyström, P. B. Zetterlund and M. R. Whittaker, J. Am. Chem. Soc., 2011, 133, 11128-11131.

36 G. Lligadas and V. Percec, J. Polym. Sci., Part A: Polym. Chem., 2008, 46, 2745-2754.

37 S. R. Samanta, V. Nikolaou, S. Keller, M. J. Monteiro, D. A. Wilson, D. M. Haddleton and V. Percec, Polym. Chem., 2015, 6, 2084-2097.

38 F. Alsubaie, A. Anastasaki, P. Wilson and D. M. Haddleton, Polym. Chem., 2015, 6, 406-417.

39 A. Anastasaki, V. Nikolaou, G. Nurumbetov, P. Wilson, K. Kempe, J. F. Quinn, T. P. Davis, M. R. Whittaker and D. M. Haddleton, Chem. Rev., 2016, 116, 835-877.

40 B. M. Rosen and V. Percec, Chem. Rev., 2009, 109, 50695119.

41 J. Laun, M. Vorobii, A. de Los Santos Pereira, O. PopGeorgievski, V. Trouillet, A. Welle, C. Barner-Kowollik, C. Rodriguez-Emmenegger and T. Junkers, Macromol. Rapid Commun., 2015, 36, 1681-1686.

42 A. Anastasaki, V. Nikolaou and D. M. Haddleton, Polym. Chem., 2016, 7, 1002-1026.

43 T. Hatano, B. M. Rosen and V. Percec, J. Polym. Sci., Part A: Polym. Chem., 2010, 48, 164-172.

44 N. H. Nguyen, X. Jiang, S. Fleischmann, B. M. Rosen and V. Percec, J. Polym. Sci., Part A: Polym. Chem., 2009, 47, 5629-5638.

45 S. R. Samanta, M. E. Levere and V. Percec, Polym. Chem., 2013, 4, 3212-3224.
46 S. R. Samanta, A. Anastasaki, C. Waldron, D. M. Haddleton and V. Percec, Polym. Chem., 2013, 4, 5563-5569.

47 M. Enayati, R. L. Jezorek, M. J. Monteiro and V. Percec, Polym. Chem., 2016, 7, 3608-3621.

48 M. Gavrilov, T. J. Zerk, P. V. Bernhardt, V. Percec and M. J. Monteiro, Polym. Chem., 2016, 7, 933-939.

49 M. Enayati, R. L. Jezorek, R. B. Smail, M. J. Monteiro and V. Percec, Polym. Chem., 2016, 7, 5930-5942.

50 N. H. Nguyen, M. E. Levere, J. Kulis, M. J. Monteiro and V. Percec, Macromolecules, 2012, 45, 4606-4622.

51 Z. Zhang, W. Wang, H. Xia, J. Zhu, W. Zhang and X. Zhu, Macromolecules, 2009, 42, 7360-7366.

52 M. E. Welch, Y. Xu, H. Chen, N. Smith, M. E. Tague, H. D. Abruna, B. Baird and C. K. Ober, J. Photopolym. Sci. Technol., 2013, 25, 53-56.

53 T. Chen, I. Amin and R. Jordan, Chem. Soc. Rev., 2012, 41, 3280-3296.

54 X. Jia, X. Jiang, R. Liu and J. Yin, ACS Appl. Mater. Interfaces, 2010, 2, 1200-1205.

55 S. Minko, M. Müller, M. Motornov, M. Nitschke, K. Grundke and M. Stamm, J. Am. Chem. Soc., 2003, 125, 3896-3900.

56 D. Usov, V. Gruzdev, M. Nitschke, M. Stamm, O. Hoy, I. Luzinov, I. Tokarev and S. Minko, Macromolecules, 2007, 40, 8774-8783.

57 F. J. Xu, L. Y. Liu, W. T. Yang, E. T. Kang and K. G. Neoh, Biomacromolecules, 2009, 10, 1665-1674.

58 S. Burkert, E. Bittrich, M. Kuntzsch, M. Muller, K. J. Eichhorn, C. Bellmann, P. Uhlmann and M. Stamm, Langmuir, 2010, 26, 1786-1795.

59 A. Anastasaki, V. Nikolaou, G. Nurumbetov, N. P. Truong, G. S. Pappas, N. G. Engelis, J. F. Quinn, M. R. Whittaker, T. P. Davis and D. M. Haddleton, Macromolecules, 2015, 48, 5140-5147.

60 A. Anastasaki, V. Nikolaou, G. S. Pappas, Q. Zhang, C. Wan, P. Wilson, T. P. Davis, M. R. Whittaker and D. M. Haddleton, Chem. Sci., 2014, 5, 3536-3542.

61 A. Anastasaki, V. Nikolaou, F. Brandford-Adams, G. Nurumbetov, Q. Zhang, G. J. Clarkson, D. J. Fox, P. Wilson, K. Kempe and D. M. Haddleton, Chem. Commun., 2015, 51, 5626-5629.

62 A. Anastasaki, V. Nikolaou, N. W. McCaul, A. Simula, J. Godfrey, C. Waldron, P. Wilson, K. Kempe and D. M. Haddleton, Macromolecules, 2015, 48, 1404-1411.

63 G. R. Jones, R. Whitfield, A. Anastasaki and D. M. Haddleton, J. Am. Chem. Soc., 2016, 138, 7346-7352.

64 J. E. Poelma, B. P. Fors, G. F. Meyers, J. W. Kramer and C. J. Hawker, Angew. Chem., Int. Ed., 2013, 52, 68446848.

65 M. Vorobii, A. de los Santos Pereira, O. Pop-Georgievski, N. Y. Kostina, C. Rodriguez-Emmenegger and V. Percec, Polym. Chem., 2015, 6, 4210-4220.

66 S. Desseaux and H.-A. Klok, Biomaterials, 2015, 44, 24-35.

67 J. E. Gautrot, B. Trappmann, F. Oceguera-Yanez, J. Connelly, X. He, F. M. Watt and W. T. S. Huck, Biomaterials, 2010, 31, 5030-5041. 
68 B. Hazer, Makromol. Chem., 1992, 193, 1081-1086.

69 C. Rodriguez-Emmenegger, O. A. Avramenko, E. Brynda, J. Skvor and A. B. Alles, Biosens. Bioelectron., 2011, 26, 4545-4551.

70 A. Aied, Y. Zheng, A. Pandit and W. Wang, ACS Appl. Mater. Interfaces, 2012, 4, 826-831.

71 M. Thomas, M. Gajda, C. Amiri Naini, S. Franzka, M. Ulbricht and N. Hartmann, Langmuir, 2015, 31, 1342613432.

72 T. Şanal, O. Oruç, T. Öztürk and B. Hazer, J. Polym. Res., 2015, 22, 3.

73 B. P. Fors and C. J. Hawker, Angew. Chem., Int. Ed., 2012, 51, 8850-8853.

74 S. O. Kyeremateng, E. Amado and J. Kressler, Eur. Polym. J., 2007, 43, 3380-3391.

75 S. O. Kyeremateng, E. Amado, A. Blume and J. Kressler, Macromol. Rapid Commun., 2008, 29, 1140-1146.
76 Z. G. Zhang, G. J. Lin and S. Bell, Macromolecules, 2000, 33, 7877-7883.

77 M. Thompson, S. Sheikh, C. Blaszykowski and A. Romaschin, in Detection Challenges in Clinical Diagnostics, ed. P. Vadgama and S. Peteu, Royal Society of Chemistry, Cambridge, 2013, ch. 1, pp. 1-34.

78 H. Ma, J. Hyun, P. Stiller and A. Chilkoti, Adv. Mater., 2004, 16, 338-341.

79 C. Rodriguez-Emmenegger, E. Hasan, O. Pop-Georgievski, M. Houska, E. Brynda and A. B. Alles, Macromol. Biosci., 2012, 12, 525-532.

80 A. A. B. Darren, M. Jones and W. T. S. Huck, Langmuir, 2002, 18, 1265-1269.

81 S. Tanuma, C. J. Powell and D. R. Penn, Surf. Interface Anal., 1993, 21, 165-176.

82 J. H. Scofield, J. Electron Spectrosc. Relat. Phenom., 1976, 8, 129-137. 